\title{
Quantum technologies of forming semantic reading strategies at students - future teachers
}

\author{
Natalia Gorlova ${ }^{1}$, Kurman Semyonov ${ }^{1}$ and Elena Yakovleva ${ }^{1, *}$ \\ ${ }^{1}$ Moscow Region State University, 10A, Radio str, 105005, Moscow, Russia
}

\begin{abstract}
The paper considers the problem of forming the semantic reading strategies at students - future teachers as that being the universal educational actions [hereinafter - UEA], which they should master in the university in order to be able to use them in teaching schoolchildren. These requirements are set forth in the Federal State Educational Standards for Higher Education [hereinafter referred to as the Standard] and in the Standards for Primary General, Basic General, Secondary General Education [hereinafter referred to as the Standards for General Education], which defines the lines of their continuity. Relevance of the problem is the need to develop of semantic reading strategies for the students - future teachers - to work with students in accordance with the requirements of General education Standards, on the one hand. On the other hand, first-year students who are starting to study pedagogy, did not study at school according to the new Standards and do not know the strategies of semantic reading. Modern children have changed a lot over the past decades (they have a new "system-semantic type of consciousness"), and in a different way than adults perceive, process and assimilate information, which requires the development of new approaches and technologies for their education and upbringing. Purpose of the paper is to reveal the essence and specifics of innovative quantum technologies aimed at forming semantic reading strategies at students - future teachers as universal educational actions, which will ensure the continuity of educational programs of general education and pedagogical education. The methodological basis of the problem under study is the psycholinguistics of child development (within the framework of the A.A. Leontyev's scientific school), which studies the issues of the interconnected development of personality and consciousness of up-to-date children in the process of mastering speech activity in the context of multilingual education (in their native, non-native, foreign language, "subject language"). In the course of the study, the following methods were used: comparative analysis of scientific papers, questionnaires, training experiment, Quantum express method, analysis and evaluation of students' activity products. The results of the study confirmed the hypothesis and proved the effectiveness of Quantum technologies for forming semantic reading strategies based on the Quantum express method. In the course of studying the discipline "Pedagogy", students mastered the strategies of semantic reading, everyone was able to prepare a "student's Pedagogical Navigator" as a product of project research activities.
\end{abstract}

\footnotetext{
* Corresponding author: e.v.yakovleva@inbox.ru
} 


\section{Introduction}

In the current conditions of globalization, multilingualism and multiculturalism, there is an acute problem of training a teacher of the "new type," who has universal competences necessary to work with students of different ages and different categories (gifted, normally, "risk groups," with special needs). The teacher of the "new type" should know the peculiarities and patterns of development of modern children; comprehend how their speech activities are arranged and functioning, how they perceive and process information; be able to create favorable conditions for the development of the students' personal and cognitive abilities in order to prepare them for life in the global information space.

In order to prepare a teacher of the "new type," it is necessary to transform the traditional, reproductive model of higher education into innovative, productive project research activities aimed at creating a student's own product.

Traditional training of the teacher for professional activity is carried out within the framework of the reproductive model, in which the teacher first gives lectures and then conducts practical (seminar, laboratory) classes, during which the acquired knowledge is sustained. On credits and examinations students demonstrate knowledge of educational material, recounting what is written in textbooks. It is still believed that after studying the theory of discipline, the student will be able to apply this knowledge himself in practice But, as shown by the pedagogical practice of students at school, they begin to use the methods and techniques that they saw at the teacher and they liked them, or which were in their personal school experience. Such a way of preparing students (we denote it "from top to bottom" - from theory to practice, from knowledge to skills) is still used in some universities.

After the introduction of the Higher Professional Education Standards in the framework of the Bologna process, a search for new approaches to organizing the process of training teachers has begun. In the context of the reform of higher education, invaluable assistance was provided by the Recommendations of foreign experts, who assessed Russian standards of the first and second generation for their compliance with modern requirements. Some of these recommendations are still relevant, for example:

- standards should reflect a qualitative rather than a quantitative outlook at education;

- they should be focused on obtaining "useful competencies", abilities, skills, and their certification;

- standards should serve as guidelines allowing the teacher to plan his/her work independently and responsibly, to manage the quality of education, etc. [15,16,17].

After the signing of the Bologna Agreement, various models of the competency-based approach are developed: in some universities, an attempt is made to radically change the process of training students - future teachers. In order to provide them with more independence, the traditional way of presenting educational information is changing: the training course begins with seminars and practical classes, and ends with lectures. The number of hours for teaching practice is increasing.

First, students make presentations, retelling what is written in the textbooks, and then the teacher gives lectures in order to generalize and systematize the knowledge gained. This way of assimilation of the program ("from bottom up") within the framework of the same reproductive model was unsuccessful, because the students, having worked out the training material in practical classes, did not show much interest in the lectures of the teacher [9].

Therefore, despite the opposite approaches to the organization of the educational process at the university ("top-down" and "bottom-up"), both approaches reflect a reproductive model of education aimed at students mastering the program content of academic disciplines using the "retelling method". On the one hand, such a way is quite justified, since a student - a future teacher must have a good knowledge of pedagogy in 
order to organize the process of upbringing and training, and, accordingly, his subject in order to "pass" it to his students. On the other hand, the reproductive model does not provide an increase in the knowledge and competencies that the student produces in the course of training, and which indicate the positive dynamics of the development of students.

The transition of higher education to a three-level model of teacher training, orientation to labor market requirements, the introduction and updating of General Education Standards and the Federal State Educational Standard of Higher Education (2018), caused the need to design new approaches, strategies, and models for preparing students for pedagogical activity $[10,18,20]$.

The General Education Standards, which point to the need for a systematic and actionoriented approach, are becoming the main guideline for preparing students for teaching activities. This approach aims the educator at:

- development of personal qualities that meet the requirements of the information society;

- development of the student's personality based on the adoption of universal educational actions in order to achieve the planned results: personal, meta-subject, subject [8].

According to these requirements, the educator must prepare the younger generation for life in the global information space and develop the ability of children to «work» with information in oral and written form. This means that priority should be given to speech rather than to teaching, which is still regarded as leading the school system.

Considering of the speech (individual and society) as a priority defines a strategic direction in education, which makes it possible to realize continuity in the development of pupils' personality and consciousness. The problem is that the Concept proposes only a classification of universal educational actions (more than 50 of them): personal, metasubject (communicative, cognitive, regulatory), subject, and psychological tests for their verification. But there is no technology to form the UEA, what contradicts the laws of didactics. In fact, according to the theory of the developmental education by L.C. Vygotsky and his followers - it is precisely the training «leads» development, not vice versa [3].

Thus, in considering the development of students' speech as a strategic direction of modern education, it is advisable to use technologies for the formation of perceptual (auditory and reading) and productive (speech and writing) speech activities. Since each speech activity is carried out through functions (communicative/regulatory, cognitive/informative) that incorporate these universal actions, this will allow monitoring of the development of UEA, which will significantly improve the quality of education.

During designing the universal technologies, the author of the paper carried out a comparative analysis of the UEA Concept and instrumental pedagogy by J. Dewey. An American scientist and practitioner proposed a system of school education "by doing", which (learning) enriches the personal experience of the child, as he masters the ways of self-knowledge of the world. According to him, the school should be a workshop, a laboratory, a school of "doing", and not "listening" [7, p. 9].

A comparative analysis of the UEA Concept and the theory by J. Dewey revealed many similarities: the development of students' cognitive motivation, domination of problem situations and tasks, development of universal actions and practical skills, learning through experimentation, etc.

The similar positions can be traced among many Russian didactic scientists involved in the development of the theory of problem education in the 60-70s of the last century, which is based on the epistemological approach to education [1,12,14]. According to this approach, the learning process is built in accordance with the process of cognition. As numerous studies have shown, teaching only on the basis of the epistemological approach 
in a mass school is not effective: if a student misses at least one lesson, then he "falls out" of the logic of cognition of the phenomenon being studied, and he has difficulty in learning.

A comparative analysis of scientific works made it possible to determine that the epistemological approach as a way of the child's natural development, the UEA Concept and instrumental pedagogy by J. Dewey have many advantages that can be used in designing of teaching technologies for the development of speech functions, including universal educational actions of students. These include: providing freedom of choice, which is important for the development of personal qualities of students, an independent search for information, increasing the communicative and cognitive motivation of students through work in pairs and groups; the development of critical thinking, communication skills and much more.

Considering that universal actions act as an instrument of cognition, rather than target guidelines, it becomes necessary to determine the planned results based on a psycholinguistic approach. These include perceptual (listening, reading) and productive (speaking, writing) types of speech activity that can be measured and evaluated, as a result of which they acquire the status of universal meta-subject competencies.

Considering the speech activity of students as a leading (strategic) one, and its types as universal meta-subject competencies, seems to be the most promising, since:

firstly, all teachers constantly use the types of speech activity in the lessons and classes: they teach children to listen and understand, speak, write, read, master subject skills and abilities;

secondly, in the course of speech activity there is a personal development and consciousnesses of students (children, pupils, students) what allows to define dynamics of personal and professional growth according to requirements of Standards of the general education and Standards of pedagogical education, providing their continuity;

third, when forming the skills of oral speech (auditing and speaking) and written speech (reading and writing), each teacher will be able to develop in students all universal metasubject actions in a complex, which are presented in the Concept of UEA.

It is obvious that in order to meet these requirements, it is important for a student as a future teacher not only to know and understand how to organize the process of personal development of each student, universal educational actions and competences, but they must possess these actions and technologies of their development in students. This is the specifics of the training of a teacher of the "new type" and pedagogical education, which should perform a predictive function, anticipating the demands of the labor market.

As indicated in the annotation, the complexity of the study was that first-year students did not study at the school according to the new Standards and did not possess semantic reading strategies as universal educational actions.

The purpose of the practical study was to develop students' semantic reading strategies by introducing the "Quantum" express method and universal Quantum technologies necessary for the future teacher to work with modern children in the educational process.

To achieve this goal, the following hypothesis was put forward:

To prepare the young generation for life in the global information space, it is necessary, first of all, to develop speech activity as a person's ability to "work with information". If a:

- types of speech activity (perceptual and productive) are considered as universal metasubject competencies;

- to use the Quantum express method for their development, this will allow students to master the Quantum technologies of forming semantic reading strategies (for students) and prepare the Student's Pedagogical Navigator as a product of design and research activities. This approach will integrate educational, professional, design, research and innovative activities of students, and will contribute to the implementation of a productive model of teacher education. 
To achieve the goal and confirm the hypothesis, the following tasks were solved:

1) identification of students' readiness to use the express methods of Quantum and Quantum technologies for the formation of strategies for semantic reading in the classes on pedagogy;

2) introduction of the express method of Quantum into the student training process and testing its effectiveness.

\section{Methods}

To identify students' readiness to use the Quantum express method to master semantic reading strategies (as part of a stating experiment), a conversation was held during which it was possible to establish that students have no idea about semantic reading strategies and universal educational actions, since they did not learn at school according to new Standards. Therefore, conducting a survey was pointless. It was found that at school they mastered the skills of oral and written speech at a fairly good level, the skills of working with educational, artistic and popular science texts.

During the conversation, students demonstrated a high level of motivational readiness to master the strategies of semantic reading, as they "want to work at school".

From the first lesson in pedagogy, a formative experiment began (the introduction of the Quantum express method), in which 92 students participated. The experiment was built on the basis of a system-activity approach (the requirement of the standards of general education). The peculiarity of the experiment and its novelty was that the students were completely immersed in their future profession: during the classes they constantly changed the roles of the teacher and students, used different pedagogical styles, teaching and upbringing methods.

At the first practice, students were asked to work out a teaching text on pedagogy using Quant 's express method. Since all practical classes in pedagogy were built according to the similarity of school lessons, students began to ask questions concerning Quant 's express method in order to get a general idea of this method and complete the task.

Students learned that "words - quanta" are found in the works of A.A. Leontiev, who refers to these units as a psycholinguistic level of language proficiency and associates them with the semantic meaning of the word [11].

In the works of C. Osgood (1956), words with the root "quantum" are also found. Osgood identified two types of mental operations: qualifying operations (between brackets) and quantifying operations (inside brackets), which correspond to different patterns of cognitive activity - the first is homeostatic, the second is multiplicative. He writes that in quantifying phrases the reference word gets a semantic coloring that is different from the coloring of the same word in isolation.

According to $\mathrm{Ch}$. Osgood, a quantum changes the semantic coloring of a statement and reflects the patterns of development of a person's cognitive activity. Therefore, A.A. Leontiev and C. Osgood associate a quantum with the semantic meaning of the word [11].

Considering the fact that the level of development of a person's speech activity depends on the level of linguistic generalizations and categorical thinking, we will consider a quantum not only as a semantic meaning of a word, but also as a unit of meaning. This approach is associated with the features and patterns of development of a new type of consciousness of modern children - a system-semantic, which is significantly different from the system-structural consciousness of children of the last century. The conceptual sphere has dominated the minds of modern children from birth, they set a "task for meaning", and quanta provide semantic processing of information and its understanding. 
As numerous observations show, modern children perceive and work out information with quanta, "grabbing" meanings and "semantic kernels" (A. Luria) from the information stream [13].

Taking into account the peculiarities and patterns of development of consciousness, personality and speech activity (within the framework of the psycholinguistics of child development) of modern children, the Quantum express method was developed as a way of working with information, which was used in different conditions [5], but was the first to form the basis of a formative experiment in 2018 as part of studying the "Pedagogy" discipline.

So, the formative experiment was carried out over two semesters (two stages). In the first semester, students mastered the basics of the Quantum express method and performed assignments in pedagogy, presenting the position of one author on a chosen topic. At the second stage (in the second semester), they conducted a comparative analysis of two or three works of domestic and foreign teachers, distinguished methodological categories, quantized information and presented the results in diagrams, tables, theses, questions / tests.

In the first lesson of the first stage, all students worked with one text, "Professional Development of a Teacher," and were divided into 4 groups to fulfill positions: keywords and concepts; chart or table; abstracts / resumes; questions / tests. After completing this task in groups, they compared the results, highlighted the keywords that needed to be presented as the core of the scheme. For a strong assimilation of information, students were asked to perform two creative positions, the Theater and the Poet, which caused a lot of positive emotions, involving the subconscious sphere of the personality.

Only after completing the assignment, students were offered a written instruction and a matrix of the Quant express method, which helped them systematize the acquired skills. This way of mastering the Quantum express method was not chosen by chance, but in accordance with the requirements of the General Education Standards.

In the second practice session, each group of students performed all six positions of the Quant express method, working with one text, and comparing the results. During the following classes, students continued to work in pairs, groups, individually, collectively; worked on pedagogical texts on different subjects, and then presented «nuclear» information in the Quantum format.

It is important to note that in the process of reading the students came to the conclusion that they used the search view as their usual way of working with information - extracting quantum meaning (how they view information on digital devices) which allowed them to process rapidly and qualitatively a large flow of information on pedagogy in a short period of time.

While working on texts, students learned how to structure information and quantize it, distinguish semantic kernels, etc. To create text compression, they used the writing skills acquired at school, recorded the results using a single Quantum algorithm, which helped other students quickly learn new information. When students presented their report, they acted as a teacher, and to fulfill a number of requirements: it was necessary not only to "convey" information to the "students", but to organize the audition process using the most effective techniques, so that all "students" participate in the lesson and were able to learn a new topic by no less than $65 \%$. The assimilation of the training material was checked using questions and the tests they developed. To consolidate the educational information, the "teacher" had to include all students in the "lesson" in communication and interaction.

During the course of mastering the Quant Express method, students learned to use various Quant-technologies to form perceptual (meaning audition and meaning reading) and productive (communication in the form of dialogue and polylogue/monologue in oral and written form) speech activities. They have been able to reduce the time spent on independent tasks. 
Thus, during the formative experiment, it was found that the regular use of the Quantum express method in practical classes allowed students to master the strategies of semantic reading as universal educational actions and Quantum - the technologies necessary for the development of perceptual (listening and reading) and productive (speaking and writing) skills in combination, which significantly increased reading literacy. Students noted that, thanks to semantic reading strategies, they began to work out educational information much faster, separating "nuclear" meaningful information from the background.

\section{Results}

As a result of the experiment, first-year students, in general, mastered the strategies of semantic reading. Each of them prepared a "Student Pedagogical Navigator", in which, according to a single Quantum algorithm (sources, keywords and concepts, theses, diagram / table and questions), all topics on pedagogy were presented.

At the end of the second stage, an intermediate cut was carried out using a questionnaire, which made it possible to determine which strategies of semantic reading students fully mastered and which ones partially.

\section{I know how:}

today's children speak, perceive, process

and assimilate information

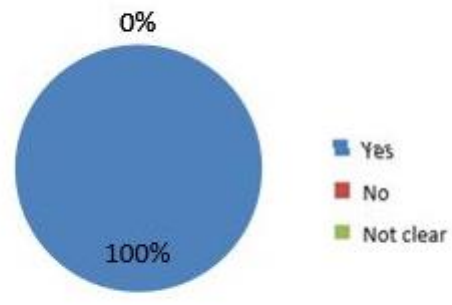

Diagram 1
2. I can do it:

process literary sources in accordance with requirements of GOST

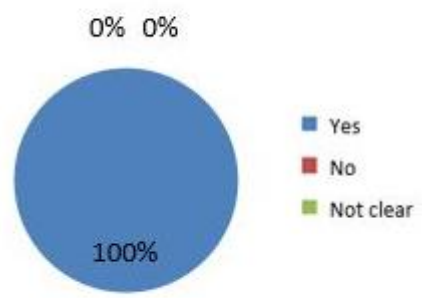

Diagram 2 
3. I can do it:

highlight keywords - quanta

(scheme components)

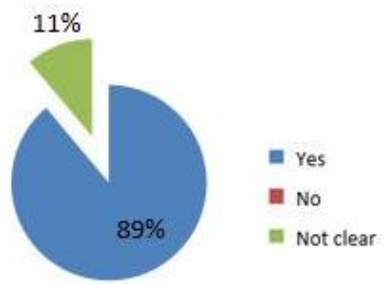

Diagram 3

5. I can do it:

highlight meaning "kernel" of

information for durable adoption

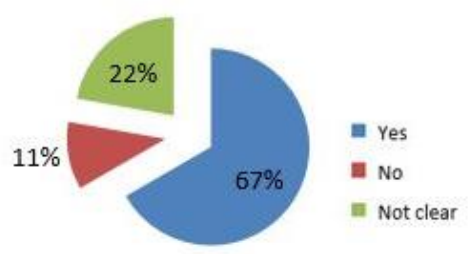

Diagram 5

7. I can:

identify "nuclear" information and

separate it from "background" one

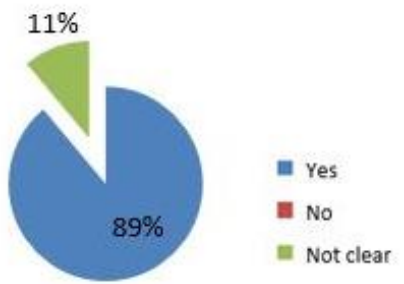

Diagram 7
4. I can do it:

structure concept and create

"matrix" of definition

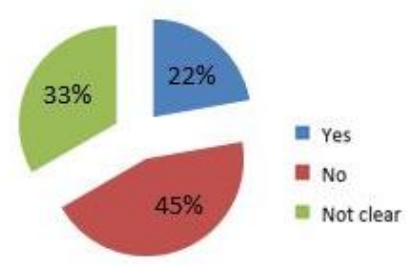

Diagram 4

6. I can do it:

portion text message

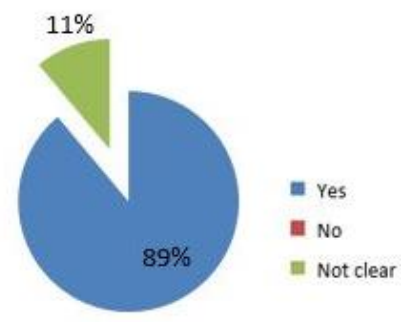

Diagram 6

8. I can:

highlight semantic "kernels" of information in text

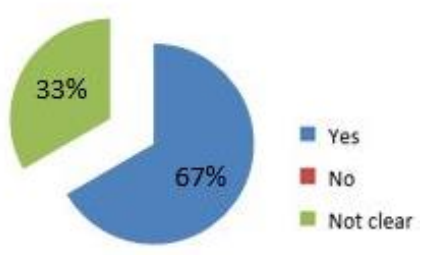

Diagram 8 
9. I can do it: present content of text as chart and table
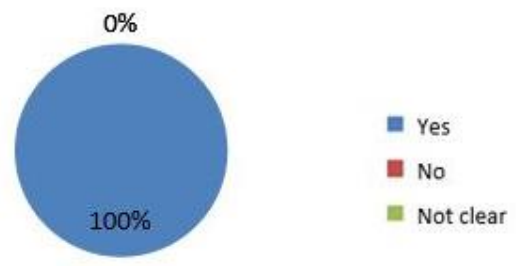

Diagram 9

11. I can:

compile abstracts and text outline, highlighting methodological categories

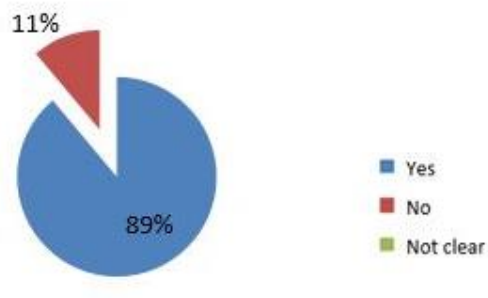

Diagram 11

13. I can:

compare approaches, theories, models, technologies, highlighting common features and methodological categories

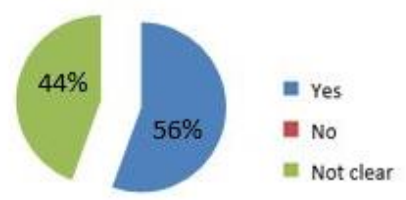

Diagram 13
10. I can do it:

draw up theses, including three parts

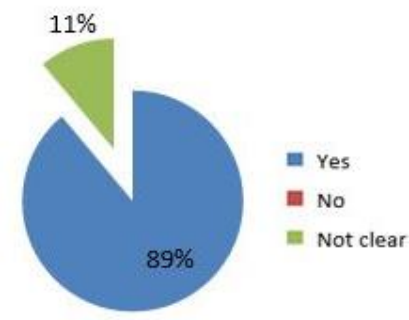

Diagram 10

12. I can:

make test tasks for text

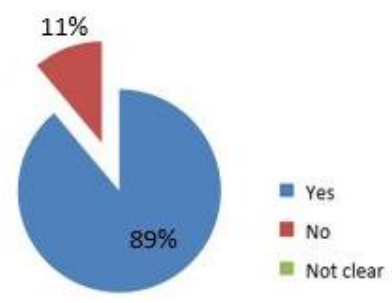

Diagram 12

14. I possess:

"QUANTUM" express method and semantic reading strategies

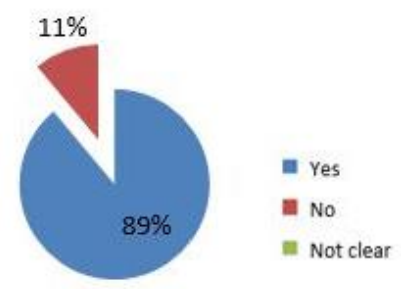

Diagram 14

Fig. 1. Diagrams.

So, the results of the student surveying presented in the diagrams indicate that the students, in general, mastered the express - method of Quantum and some Quantum technologies. Their greatest difficulty was caused by such strategies as the ability to structure the concept and create a "matrix" of definition; highlight semantic kernels of information in the text; Compare approaches, theories, models, and technologies, highlighting common features and methodological categories. It is quite natural that first-year students have not yet been able to fully master these strategies, since they reflect the level of formation of methodological thinking. The formation of methodological thinking, methodological culture takes place throughout the entire course of study at the university when studying different disciplines on a meta-disciplinary basis. 


\section{Discussion}

In this section, we will consider a discussion question concerning different approaches to the formation of semantic reading strategies. In the psychological concept of universal educational actions (A. G. Asmolov, G. V. Burmenskaya, I. A. Volodarskaya, etc.), semantic reading is interpreted as understanding the purpose of reading and choosing the type of reading depending on the goal [8]. But, unfortunately, it is not specified what types of reading we are talking about. Different types of reading, depending on the goal, are presented only in the methodology of teaching foreign languages [4].

According to the philologist Smetannikova N. N., possession of semantic reading skills contributes to the development of oral speech and, as a result, - writing and productive learning. Highlighting the ways of semantic reading (analytical or structural, synthetic, or interpretive; critical, or evaluative), the author calls semantic reading reflexive. At the same time, Smetannikova N. N. does not give a clear characteristic of semantic reading and its difference from other types; it does not indicate how the methods and skills of semantic reading relate to strategies [19].

When teaching semantic reading, she suggests using the traditional approach: pretext, text, and post-text tasks that are not related to semantic reading strategies.

Smetannikova N. N. believes that the purpose of semantic reading is to accurately and fully understand the content of the text, to catch all the details and practically comprehend the information. This definition of semantic reading is controversial. Understanding, according to N.I. Zhinkin, is one of the three mechanisms of speech, and manifests itself "in the aggregate of two complementary links: analysis and synthesis." Consequently, the mechanism of comprehension must be developed among students in order to master all types of speech activity, including reading. And such a task as "catching all the details" is posed when studying the form of reading.

In general, we can conclude that Smetannikova N.N., proposes the wording of the "semantic reading strategy" from the perspective of teaching Russian language and literary reading, and outlines in her textbook the traditional technology for teaching reading literary texts aimed at developing reading skills.

A different approach is presented in the dissertation research by Borisova S.V., devoted to the formation of strategies for semantic reading of texts in younger students (based on German language material). The author analyzes the goals of reading instruction in a primary school (grades 5-9) - introductory, viewing, studying, searching, and concludes that the goal of teaching reading to younger students is not presented in the Foreign Language Standards. Borisova S.V. based on research A.A. Leontyev on a unified approach to teaching subjects of the language cycle, at the works of N.A. Gorlovoy on the semantic method of teaching reading (in the native and foreign languages) to children of preschool and primary school age. Following the scientists, she suggests considering semantic reading as the goal of learning and a means of developing the personality of younger students.

Borisova S.V. defines "semantic reading as a process of perceiving graphically formatted textual information and its processing into personal-semantic settings in accordance with the communicative-cognitive task". A deep and thorough analysis of research by foreign and domestic scientists allowed Borisova S.V. determine the essence of semantic reading strategies; highlight the mechanisms of semantic reading, typology of strategies [2].

To understand the essence of the method of semantic reading, we compare it with the traditional method of teaching reading - analytical and synthetic, proposed by D. B. Elkonin, which is focused on the formation of two sides of reading: technical and substantive / semantic. In the methodology of teaching the Russian language, the terms "substantial" and "semantic" side of reading are used as synonyms. Learning to read 
according to the traditional method is built in such a way that at first the children develop the technical side (reading technique), and then the content (semantic). It was believed that if a child reads quickly, he will be able to understand and comprehend what he read. Therefore, semantic reading is presented in the concept of universal educational actions and in the works of N. Smetannikova as one of the sides of the reading process, and not as an independent type of speech activity.

Given the new type of consciousness of modern children (system - semantic) and the dominance of the semantic sphere in the child's consciousness as the ability to set a "task for meaning", when teaching semantic reading at the initial stage, it is necessary to integrate the technical and substantive aspects of reading and form a personal attitude in the child to comprehend the textual information. Using the method of semantic reading for modern children will gradually formulate strategies for semantic reading, which will significantly increase reading motivation and functional literacy of students [6].

\section{Conclusions}

The paper presents an innovative approach to the training of a "new type" teacher: firstyear students mastering Quantum - technologies for the formation of semantic reading strategies as universal educational actions based on the Quantum express method in the course of studying pedagogy.

At the end of the second stage of the experiment, after repeated questioning, students expressed their opinion about the express - method of Quantum. They said that at first, they did not understand why it was necessary to carry out different tasks on one text, then on another; that gradually they began to notice how they learned to quickly process educational texts, isolate the main thing, structure and quantize information. During the conversation, students reported that they began to gradually use the Quantum express method and the acquired strategies of semantic reading in classes in other disciplines. They came to the conclusion that the use of Quantum - technologies for the formation of listening, speaking, reading and writing skills in the complex in the lessons on pedagogy contributed to the development of universal meta-subject competencies (perceptual, productive, interactive). This technology gives students great opportunities to use them in the formation of semantic reading strategies for students of different ages and different categories (gifted, normally, "risk groups" with special educational needs).

The perspective of the research is to explore the research potential of Quantum technologies in the formation of personality qualities, methodological and critical thinking in schoolchildren and students, creativity, collaboration, communication and interactive competences.

\section{Acknowledgements}

I am grateful to the esteemed co-authors - Semyonov Kurman Borisovich and Yakovlev Elena Valerievna for introducing the Quantum Express method into the educational process of training teachers in other faculties. This allowed us to increase the possibilities of using Quantum technology in other settings and to judge the reliability and credibility of the results obtained.

We thank our wonderful students for their creative approach in pedagogy, for their interesting insights in problem solving, for their interest in pedagogical science and Quantum technology. 
Finally, we express our deep gratitude to the management of the University for the opportunity to test and introduce innovative developments into the educational process of preparing students for pedagogical activities.

\section{References}

1. Karlheinz Barth, Lernschwächen früh erkennen im Vorschulß und Grundschulalter- 4 Fuflage (Verlag München Basel, Ernst Reinhardt)

2. S.V. Borisova, Formation of strategies for semantic reading of textual information in elementary school students (based on German language material). Abstract of diss. for degree of Cand. ped Science (M., 2012)

3. L.S. Vygotsky, Thinking and Speech. Psychological research (M., Labyrinth, 1996)

4. N.D. Galskova, N.I. Gez, Theory of teaching foreign languages. Lingua didactics and methodology: textbook for students (M., Publishing Center "Academy", 2009)

5. N.A. Gorlova, Psycholinguistic fundamentals of teaching foreign languages to preschool children. Teaching aid. (M., MGIU, 2001)

6. N.A. Gorlova, Primer for modern children. With guidelines for teaching reading (M., School Press, 2011)

7. J. Dewey, Democracy and education: Per. from English (M., Pedagogy - Press, 2000)

8. How to design universal learning activities in elementary school. From action to thought: manual for teacher (M., Education, 2011)

9. Competency-based approach in teacher education. Collective Monograph (St. Petersburg, Publishing House of Russian State Pedagogical University named after A.I. Herzen, 2005)

10. V.E. Kuznetsova, Science for benefit of mankind. Collection of scientific articles by teachers and graduate students following International Scientific Conference of Young Scientists, Postgraduates and Students (2018)

11. A.A. Leontiev, Language, speech, speech activity. 3rd edition (M., KomKniga, 2005)

12. I.Ya. Lerner, Problematic education (M., 1974)

13. A.R. Luria, Language and consciousness (Moscow, Publishing House of Moscow State University, 1998)

14. A.M. Matyushkin, Thinking, learning, creativity (M., Publishing House "MPSI", MODEK, 2003)

15. Updating education in Russia (Regional level) 18666-RU (World Bank Document)

16. Reform and development of higher education (UNESCO Program Document, 1995)

17. Russia: education in transition. World Bank Staff and Advisers Report (1995)

18. K.B. Semenov, M.M. Urusova, Modern problems of psychological and pedagogical education. Materials of 4th regional scientific-practical conference (on 100th anniversary of professional teacher education in Dagestan): in 5 parts (Makhachkala, 2017)

19. N.N. Smetannikova, Teaching reading strategies in grades 5-9: how to implement the FSES: a manual for teacher (M., Balass, 2011)

20. Federal state educational standards of higher education in areas of undergraduate 3 ++ , http://www.fgosvo.ru 